\title{
THE INFLUENCE OF THE PROCESSING PARAMETERS ON THE POROSITY AND MICROHARDNESS OF SINTERED TI-20Nb BIOMEDICAL ALLOY
}

\author{
${ }^{1}$ Ljerka SLOKAR BENIĆ, ²Gorana DOMITROVIĆ, ${ }^{3 Z \text { iga ERMAN, }{ }^{4} J a d r a n k o ~ S ̌ U B I C ́ ~}$ \\ 1 University of Zagreb Faculty of Metallurgy, Sisak, Republic of Croatia, EU, slokar@simet.unizg.hr \\ 2University of Zagreb Faculty of Metallurgy, Sisak, Republic of Croatia, EU, goranad82@gmail.com \\ ${ }^{3}$ University of Ljubljana Faculty of Natural Sciences and Engineering, Ljubljana, Slovenia, EU, \\ ziga.erman@magneti.si
}

4EImech-Sintermak Ltd., Zagreb, Croatia, EU, sintermak@sintermak.hr

https://doi.org/10.37904/metal.2020.3581

\begin{abstract}
Titanium based alloys are increasingly used in biomedicine due to their favourable properties. However, because of their high cost, new methods are being developed to produce more economical alloys. Therefore, in the framework of this work, Ti-20Nb alloy was produced by powder metallurgy. Namely, experimental alloy was prepared by mechanical alloying in a ball mill. The samples were singled out from the powder mixture and pressed on a hydraulic press. Sintering was carried out in a tube furnace in an argon atmosphere. Different processing parameters regarding the time and temperature of sintering were applied. Chemical homogeneity was analysed using the energy-dispersive spectrometry. Porosity was observed using the light microscope and microhardness was determined by Vickers method. The obtained results show that with a small correction of the applied technological parameters, in terms of time extension of mixing/mechanical alloying, it is possible to produce economically $\mathrm{Ti}-20 \mathrm{Nb}$ alloy having the properties suitable for biomedical application by using powder metallurgy technology.
\end{abstract}

Keywords: Powder metallurgy, titanium alloys, biomedical alloys, porosity, microhardness

\section{INTRODUCTION}

Although it is biocompatible and has other favourable properties, commercially pure titanium does not have sufficient strength properties needed for biomedical applications. Besides, the main problem why it is not wider used lies in its high price, which results from a complex and therefore expensive manufacturing process of elemental titanium [1,2]. Therefore, to solve this problem in terms of properties improvement various elements were added to titanium [1,3-7] Niobium is known as stabilizer of $\beta$ phase of titanium and it can form a homogenous solid solution with titanium. Also, it is non-toxic and non-allergic element $[8,9]$. Further, to reduce the costs generally, that is to reduce or eliminate the machining costs and to minimize the waste of alloy, powder metallurgy technology can be used $[1,2,8]$.

The aim of this study is to determine the parameters of particular powder metallurgy processes (sintering time and temperature) to achieve the microhardness of sintered alloy suitable for biomedical applications.

\section{MATERIALS AND METHODS}

The alloy of interest in this paper is Ti-20Nb (Table 1) produced by powder metallurgy. For this purpose, four samples were prepared from elemental powders (Table 2) using different processing parameters (Table 3). Mechanical alloying was performed in a ball mill at room temperature at the rotation rate of $200 \mathrm{rpm}$ for 30 
minutes. The protective atmosphere of argon was used to prevent the oxidation of powders. In an attempt to minimize the costs and ensure the low-cost powder metallurgy procedure, no lubricant was added.

Table 1 Chemical composition of experimental alloy (at\%)

\begin{tabular}{|c|c|c|}
\hline Element & $\mathrm{Ti}$ & $\mathrm{Nb}$ \\
\hline At. $\%$ & 80 & 20 \\
\hline
\end{tabular}

Table 2 Elemental powders characteristics

\begin{tabular}{|c|c|c|c|c|}
\hline Material & $\begin{array}{c}\text { Purity } \\
(\%)\end{array}$ & $\begin{array}{c}\text { Particle size } \\
(\mu \mathrm{m})\end{array}$ & Particle shape & $\begin{array}{c}\text { Density } \\
\left(\mathrm{g} / \mathrm{cm}^{3}\right)\end{array}$ \\
\hline Ti powder & 99.8 & $45-75$ & Spherical & 4.51 \\
\hline Nb powder & 99.9 & $<65$ & Spherical & 8.57 \\
\hline
\end{tabular}

Table 3 Pressing and sintering parameters

\begin{tabular}{|c|c|c|c|}
\hline Sample No. & $\begin{array}{c}\text { Compacting pressure } \\
(\mathrm{MPa})\end{array}$ & $\begin{array}{c}\text { Sintering temperature } \\
\left({ }^{\circ} \mathrm{C}\right)\end{array}$ & $\begin{array}{c}\text { Sintering time } \\
(\mathrm{h})\end{array}$ \\
\hline 1 & 80 & 1100 & 2 \\
\hline 2 & 80 & 1350 & 2 \\
\hline 3 & 80 & 1100 & 4 \\
\hline 4 & 80 & 1350 & 4 \\
\hline
\end{tabular}

After milling, four samples of cylindrical shape were prepared by uniaxial pressing of powder mixture in stainless steel die at room temperature. The powder densification was accomplished in that way. After that, green compacts were sintered in a tube furnace in a protective atmosphere of argon ( $99.99 \%$ purity). Sintering temperature (Table 3) was chosen to be in the beta titanium region [8], since it is known that the titanium beta phase ensures the suitable properties for biomedical applications. The sintering procedure consisted of three stages. The first stage included the heating of the samples at rate of $10^{\circ} \mathrm{C} / \mathrm{min}$ up to sintering temperature. In the second stage samples were held for an hour at constant temperature. In the third stage samples were cooled in the furnace to the room temperature.

The porosity of sintered samples was observed using the light microscope equipped with digital camera at magnification of $100 \mathrm{x}$. For that purpose, samples were metallographically prepared by standard procedure of grinding and polishing. The microhardness of polished samples was determined by Vickers method under the load of $19.60 \mathrm{~N}(\mathrm{HV} 2)$ during $10 \mathrm{~s}$ and diagonals of imprints were measured at magnification of $500 \mathrm{x}$.

\section{RESULTS AND DISCUSSION}

The goal of this research is to determine sintering time and temperature of low-cost powder metallurgy process for producing the porous Ti-20Nb biomedical implant. In order to verify the homogeneity of mixture of titanium and niobium powders after compacting the energy-dispersive spectrometry (EDS) was performed. For that purpose, EDS analysis of green compacts was carried out in 10 points. In each point resulting EDS spectrum was almost the same and this is shown in Figure 1.

The sintered polished samples were observed using the light microscope at magnification of $100 \mathrm{x}$. The micrographs shown in Figure 2 were taken by digital camera. These micrographs show dark areas representing pores located along the grain boundaries. As it can be seen in Figure 2, the pores are small in size and of irregular shape. They are also interconnected in some places. The reason for this can be found in a poor densification of material during sintering. 


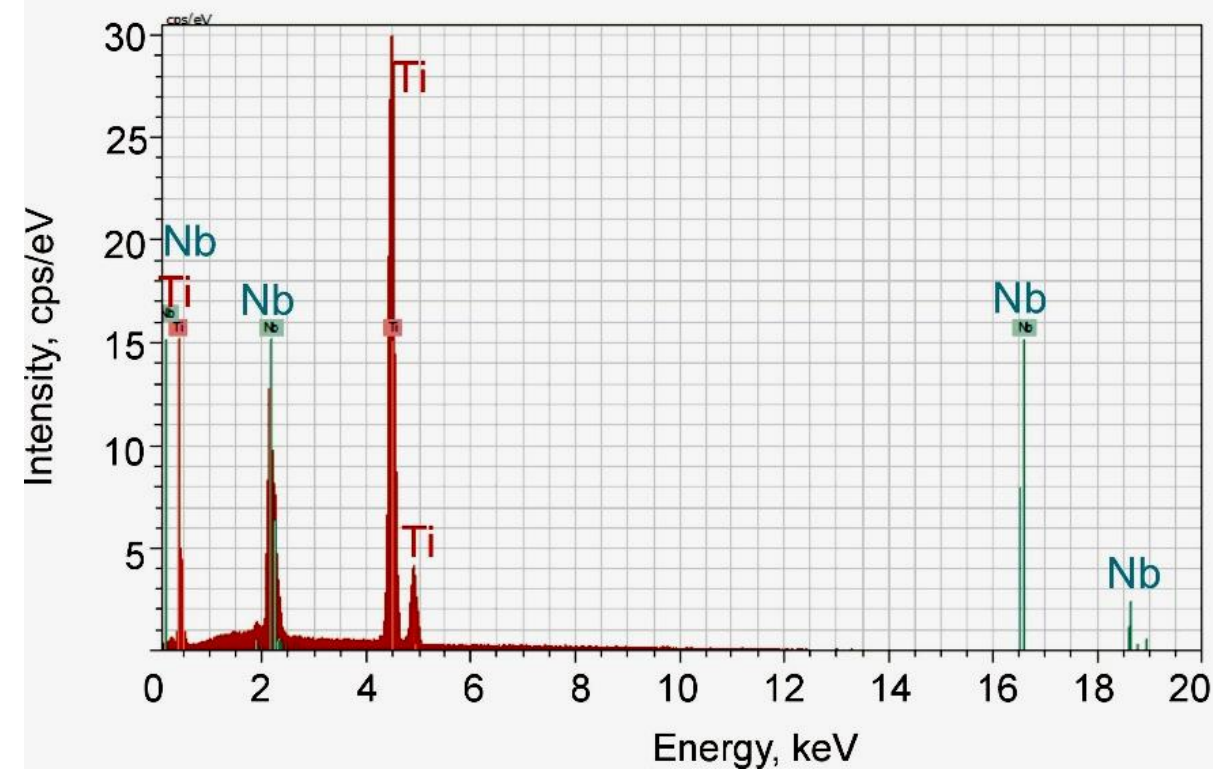

Figure 1 EDS spectrum of Ti-20Nb powder mixture

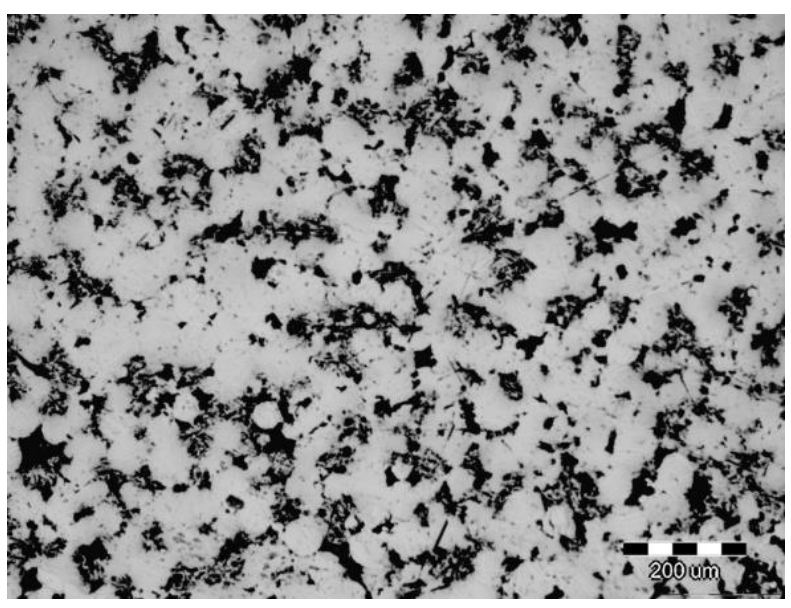

a) Sample No. 1

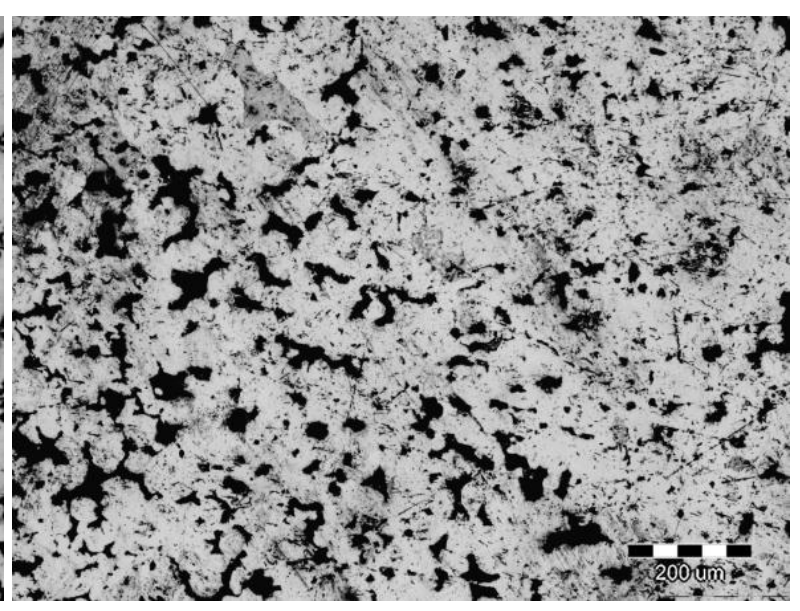

b) sample No. 2

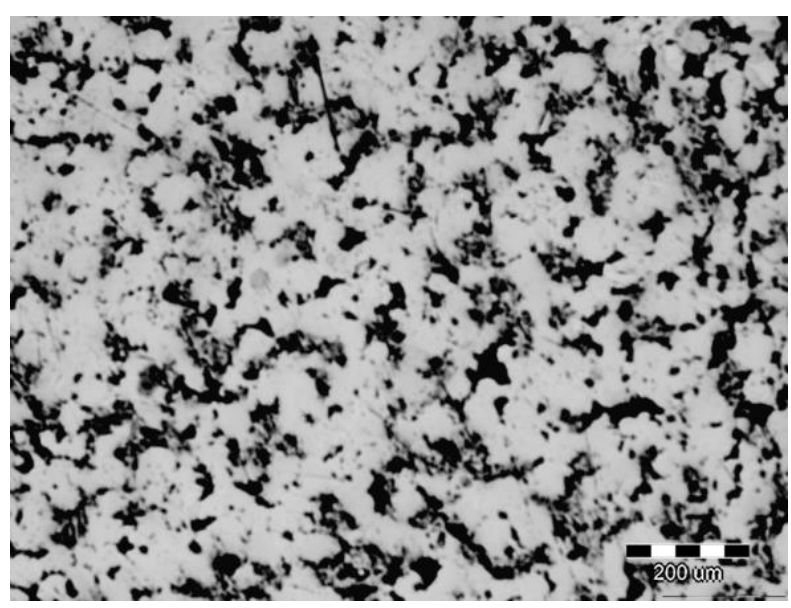

c) Sample No. 3

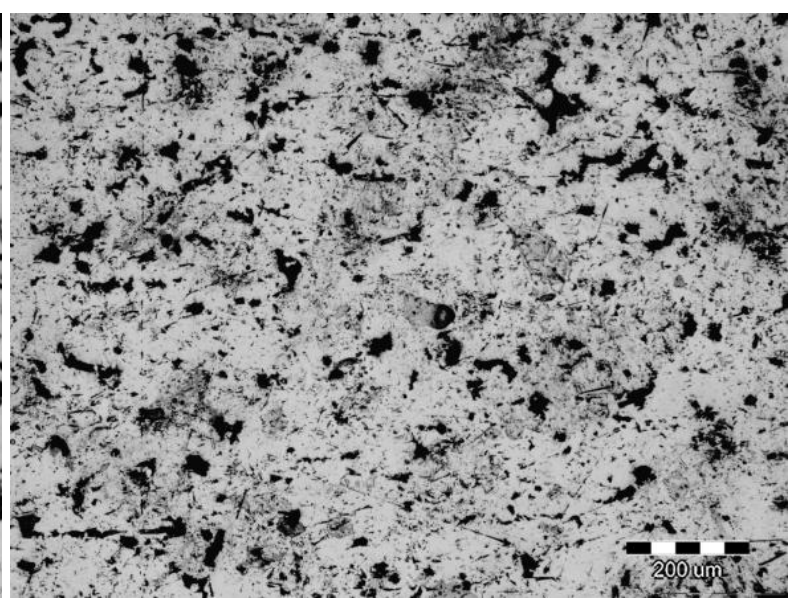

d) Sample No. 4

Figure 2 Morphologies of pores 
Further, Figure 2 shows that portion and size of pores are smaller in samples No. 2 and No. 4 which are sintered at higher temperature $\left(1350^{\circ} \mathrm{C}\right)$. Otherwise, the pores become spherical and disappear in the last sintering stage. A certain amount of pores that are not spheroidized is present, indicating that the last sintering stage was not completed. A reason for this can be found in several factors, such as: chemical composition of powders, geometry and density of green compact, an atmosphere in a sintering furnace and sintering temperature as well [2]. Generally, a porous sample is characterized by the interconnection of pores, which is an important criterion for achieving a porous implant that will allow the smooth transfer of body fluids in the body.

Microhardness of sintered polished samples was measured by Vickers method in five spots and average values, listed in Table 4, were calculated.

Table 4 Microhardness HV2 of sintered samples

\begin{tabular}{|c|c|c|c|c|}
\hline Sample No. & 1 & 2 & 3 & 4 \\
\hline HV2 & $167 \pm 2$ & $200 \pm 1$ & $88 \pm 4$ & $205 \pm 1$ \\
\hline
\end{tabular}

These results show that microhardness values are in the range of $88-220 \mathrm{HV} 2$. A low value for sample No. $3(88 \mathrm{HV} 2)$ is expected regarding its non-compactibility and rupture after sintering. Namely, the part of sample No. 3 broke off after sintering. A high value for sample $8(220 \mathrm{HV} 2)$ was also expected because it was sintered at a higher temperature for a longer time. This range of microhardness values is similar to that for $\mathrm{Ti}-\mathrm{Nb}-\mathrm{Zr}$ alloys in [7], which showed other mechanical properties favourable for biomedical applications.

Figure 3 graphically shows the dependence of the measured microhardness on sintering temperature. This graph clearly shows that the microhardness of the samples sintered at a higher temperature is greater than the microhardness of the samples sintered at a lower temperature. An increase in microhardness with sintering temperature was also observed in papers $[6,10]$.

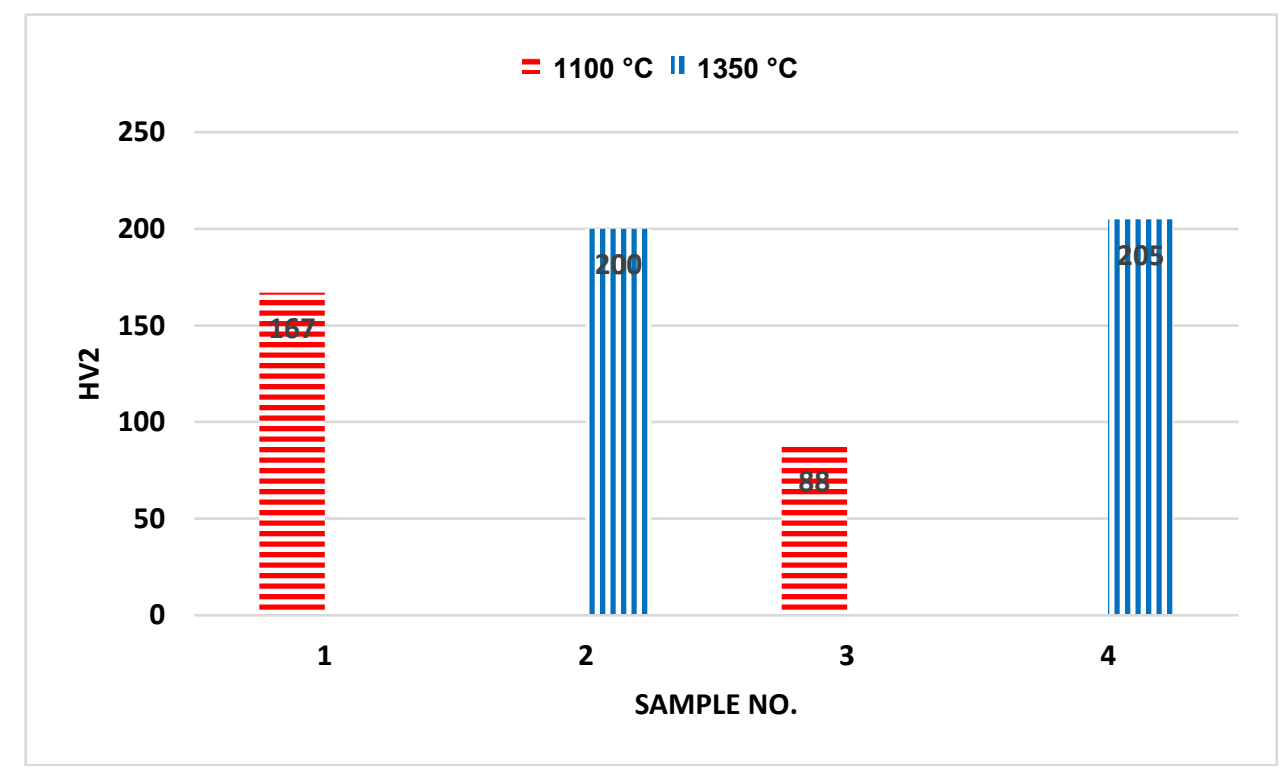

Figure 3 Dependence of microhardness on sintering temperature

Generally speaking, the microhardness of sintered specimens increases as temperature rises because sintering at higher temperatures promotes additional particle bonding and is more complete due to higher diffusion rates and mass transfer [10]. However, sintering temperature should not be too high, that is, at the 
upper limit of the $\beta$-Ti region, as this would probably result in too high microhardness values for biomedical applications.

Considering the influence of sintering time on the microhardness, which is shown graphically in Figure 4, if sample 3 which breaks off is excluded, it can be said that longer sintering time leads to slightly higher microhardness values.

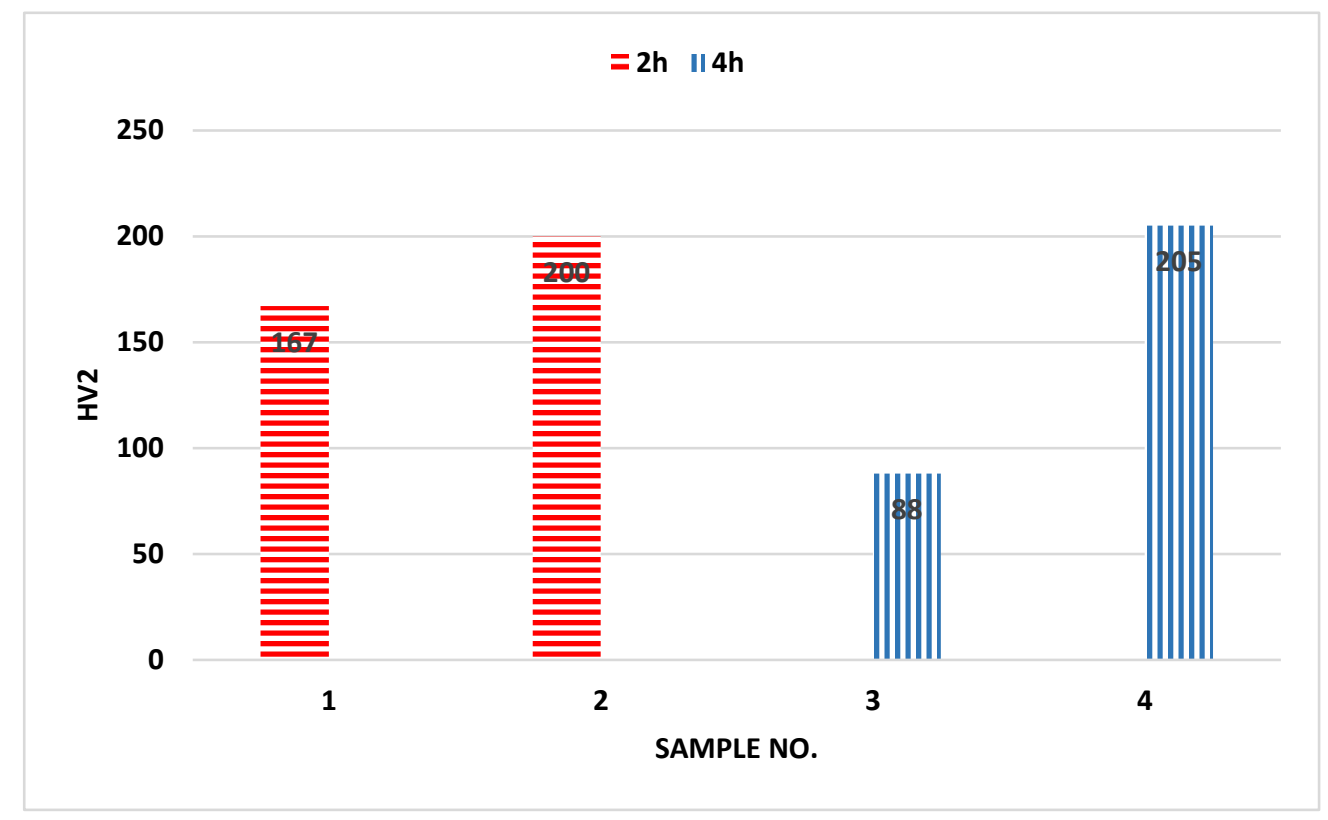

Figure 4 Dependence of microhardness on sintering time

This behaviour can be related to the fact that longer sintering time provides a more complete interparticle bonding, that is, alloying, thus highlighting the influence of the niobium as an alloying element on the titanium through the formation of a solid solution of $\beta(\mathrm{Ti}, \mathrm{Nb})$.

\section{CONCLUSIONS}

In this paper four samples of Ti-20Nb alloy were prepared by powder metallurgy with purpose of its characterization for potential biomedical application. From the presented results the followed can be concluded:

- $\quad$ porous samples were obtained by the applied processing conditions,

- higher sintering temperature resulted in smaller fraction and size of pores in sintered samples,

- microhardness of sintered samples increases with the increased sintering temperature as well as with the increased sintering time.

Finally, the processing parameters of a cost-effective mechanical alloying applied in this research makes it possible to produce sintered low-cost Ti-20Nb alloy potentially suitable for biomedical applications, with small correction of the applied parameters, in terms of extending the mixing / mechanical alloying time.

\section{ACKNOWLEDGEMENTS}

The authors would like to thank the „Magneti Ljubljana Ltd." and „Alas-Info Ltd." for their kind support during the samples preparation and sintering. 


\section{REFERENCES}

[1] WALLY, Z.J., VAN GRUNSVEN, W., CLAEYEESNS, F., GOODAL, R., REILLY, G.C. Porous titanium for dental implant applications. Metals. 2015, vol. 5, pp. 1902-1920.

[2] DEWIDAR, M. Influence of processing parameters and sintering atmosphere on the mechanical properties and microstructure of porous 316L stainless steel for possible hard-tissue applications. International Journal of Mechanical \& Mechatronics Engineering. 2012, vol. 12, no. 1, pp. 10-24.

[3] YEMISCI, I., MUTLU, O., GULSOY, N., KUNAL, K., ATRE, S., GULSOY, H.O. Experimentation and analysis of powder injection molded Ti10Nb10Zr alloy: a promising candidate for electrochemical and biomedical application. Journal of Materials Research and Technology. 2019, vol. 8, no. 6, pp. 5233-5245.

[4] YANG, D., GUO, Z., SHAO, H., LIU, X., JI, Y. Mechanical properties of porous Ti-Mo and Ti-Nb alloys for biomedical application by gelcasting. Procedia Engineering. 2012, vol. 36, pp. 160-167.

[5] ADAMEK, G. Mechanical alloying of Ti-20Ta-20Nb-(10-20)Mg alloys. Acta Physica Polonica A. 2014, vol. 126 , no. 4, pp. 871-874.

[6] BOLZONI, L., HERRAIZ, E., RUIZ-NAVAS, E.M., GORDO, E. Study of properties of low-cost powder metallurgy titanium alloys by 430 stainless steel addition. Materials and Design. 2014, vol. 60, pp. 628-636.

[7] RAO, X., CHU, C.L., ZHENG, Y.Y. Phase composition, microstructure and mechanical properties of porous Ti$\mathrm{Nb}-\mathrm{Zr}$ alloys prepared by a two-step foaming powder metallurgy method. Journal of the Mechanical Behavior and Biomedical Materials. 2014, vol. 34, pp. 27-36.

[8] BAKER, H. Alloy Phase diagrams. ASM Handbook, vol. 3, ASM International, Ohio, 2006.

[9] FELLAH, M., HEZIL, N., TOUHAMI, M.Z., OBROSOV, A., WEI $\beta$, S., KASHKAROV E.B., LIDER, A.M., MONTAGNE, A., IOST, A. Enhanced structural and tribological performance of nanostructured Ti-15Nb alloy for biomedical applications. Results in Physics. 2019, vol. 15, 102767.

[10] SANTOS, D.R., PEREIRA, M.S., CAIRO, C.A.A., GRACA, M.L.A., HENRIQUES, V.A.R. Isochronal sintering of the blended elemental Ti-35Nb alloy. Materials Science and Engineering A. 2008, vol. 472, pp. 193-197. 